\title{
Prevalens av depresjon hos eldre: en kort oversikt basert på erfaringer med epidemiologisk forskning fra Helseundersøkelsen i Nord-Trøndelag (HUNT)
}

\author{
Eystein Stordal $^{1,2}$, Hanne I. Solhaug ${ }^{1}$, Ingunn Bosnes ${ }^{1}$ og Anne Følstad ${ }^{1}$ \\ 1) Psykiatrisk klinikk, Alderspsykiatrisk enhet, Sykehuset Namsos \\ 2) Institutt for nevromedisin, Det medisinske fakultet, Norges teknisk-naturvitenskapelige universitet, Trondheim \\ Korrespondanse: Eystein Stordal, Psykiatrisk klinikk, Alderspsykiatrisk enhet, Sykehuset Namsos, 7800 Namsos \\ E-post: eystein.stordal@hnt.no Telefon: 47-74215400
}

\section{BAKGRUNN}

Depresjonssykdom og depresjonssymptomer er hyppig forekommende hos eldre og studier de siste tiårene gir holdepunkter for en økning av prevalens av depresjon i den eldre befolkning (1-5). I epidemiologiske studier varierer den målte prevalensen av depresjon $i$ forhold til alder og kjønn. Ulike studiedesign, innsamlingsrutiner, populasjonens sammensetning og måleinstrumenter er noen mulige årsaker til den store variasjonen $\mathrm{i}$ funnene.

Depresjon er et sammensatt syndrom med somatiske, psykologiske, kognitive og sosiale symptomer. De depressive symptomene er ikke spesifikke for depresjonssykdom. De sentrale somatiske symptomene som manglende energi, redusert matlyst og redusert søvn forekommer også ved mange somatiske lidelser, på samme måte som konsentrasjonsvanskeligheter og redusert oppmerksomhet også forekommer ved kognitive lidelser som demens. Dette gjør studier av prevalens av depresjon i den eldre del av befolkningen krevende.

Depresjon forekommer som egen sykdom, men er også en hyppig forekommende komorbid lidelse til somatisk eller kognitiv lidelse. Depressive symptomer forekommer hyppig som ledsagende symptom til kroniske somatiske sykdommer og funksjonssvikt (for eksempel nedsatt hørsel og syn) (6,7). Depressive symptomer er også vanlig i første fase av Alzheimer demens og andre kognitive lidelser.

Depresjonssykdom og depresjonssymptomer medfører stor lidelse og redusert psykososial funksjon, i tillegg til at det påvirker behandling og forløp av somatisk sykdom (for eksempel hjerte-karlidelser, metabolsk syndrom med mer). Også for samfunnet fører depresjonslidelser til store kostnader (pleie og omsorgskostnader, redusert produktivitet, lengre sykdomsforløp ved somatiske sykdommer). I såkalte "cost-of-illness" studier er depresjon en av de mest kostbare sykdommer (8).

I denne artikkelen er målsettingen å gi en oversikt over prevalens av depresjon i den eldre befolkning slik det fremgår av psykiatrisk epidemiologisk forskning. $\mathrm{Vi}$ avgrenser dette til studier av forekomst $\mathrm{i}$ den generelle befolkning. Vi bygger på egen erfaring med studier av depresjon i befolkningen basert på data fra
Helseundersøkelsen i Nord-Trøndelag (HUNT) og en gjennomgang av noen utvalgte publikasjoner fra andre store befolkningsstudier og oversiktsartikler.

\section{PreValens AV DePRESJON I TVERRSNITTS- STUDIER MED SYMPTOMSKALAER SOM MÅLEINSTRUMENT}

De mest vanlige måleinstrumenter i store epidemiologiske studier av depresjon hos eldre er Center for Epidemiological Studies Depression Scale (CES-D) (9), Hospital Anxiety and Depression Scale (HADS) (10) og Geriatric Depression Scale (GDS) (11). Kasus av depresjon blir definert over et definert grense-skåre (cut-off) (12). Mens GDS er utviklet med spesielt utvalgte symptomer på depresjon hos eldre, er CES-D og HADS utviklet for å måle depresjon i hele den voksne befolkning. Både CES-D og HADS er validert og funnet godt egnet til måling av depresjon hos eldre (13).

I HUNT ble depresjon målt med depresjon subskala av Hospital Anxiety and Depression Scale (HADS-D). I HUNT-2 studien fant vi en tilnærmet lineær økning av depresjon over hele den voksne befolkning med prevalens på omkring 4\% i yngste aldersgruppe (20-29 år) til omkring 20\% i eldste aldersgruppe (80-89 år). Blant de eldre over 60 år målte vi prevalens av depresjon til omkring 17\%, økende fra 14\% i aldersgruppen 60-69 år til 20\% i aldersgruppen 80-89 år. I HUNT-studien fant vi ingen vesentlig kjønnsforskjell på HADS definert depresjon (1).

I en nylig publisert oversiktsartikkel i Journal of Affective Disorders over studier av depresjon blant eldste eldre (over 75 år) fant Luppa og medarbeidere (4) en variasjon i prevalens av depresjon mellom 4,5\% og $37,4 \%$ i store symptomskala baserte epidemiologiske studier. Gjennomsnittet var 17,1\%. Denne oversiktsartikkelen bygger på 14 store internasjonale studier publisert etter år 2000 med god metodisk kvalitet, HUNT-undersøkelsen inngår i analysen. I motsetning til i HUNT-studien rapporterer de andre studiene som inngikk i oversiktsartikkelen en kjønnsforskjell med større forekomst av depresjon hos kvinner sammenlignet med menn med en kjønnsratio på ca. 1,5. Luppa fant også geografiske forskjeller på forekomst av depresjon, med lavest forekomst i studier fra USA, Frank- 
rike og Norge, og høyest forekomst i Italia og Japan.

Resultatene fra disse nyere epidemiologiske undersøkelsene skiller seg ikke vesentlig fra resultatene fra to klassiske studier av eldres depresjon fra Nederland og USA som begge brukte CES-D som måleinstrument. I Longitudinal Aging Study Amsterdam (LASA) fant de en prevalens på 14,9\% i aldersgruppen 55-85 år (14). I USA ble eldre over 65 år undersøkt på depresjon på fire forskjellige geografiske steder $i$ the Established Populations for Epidemiologic Studies of the Elderly (EPESE) $(15,16)$, hvor man fant en variasjon $i$ prevalens fra $9,0 \%$ til $15,1 \%$. I LASA-studien fant man en økning i prevalensen fra aldersgruppen 55-59 år til de i aldersgruppen 80-89 år, mens EPESE-studien ikke rapporterte noen endring med økende alder.

\section{PreVAlens AV DEPRESJON I TVERRSNITTS- STUDIER MED DIAGNOSTISK INTERVJU SOM MÅLEINSTRUMENT}

Diagnosen depresjon bygger i disse studiene på de diagnostiske kriteriene i diagnosesystemene ICD og/eller DSM. For å undersøke om diagnosen depresjon foreligger på en systematisk og reliabel måte, er det gjennomført et strukturert diagnostisk intervju. Det foreligger ulike diagnostiske intervjuer og Composite International Diagnostic Interview (CIDI) (17) er hyppigst brukt $\mathrm{i}$ de store epidemiologiske studiene. Felles for disse intervjuene er at de er tilpasset diagnosesystemene og gjennomføres likt $i$ alle aldersgrupper. Det spørres spesifikt om tid for de depressive symptomer, slik at både punktprevalens, 3 måneders-, 6 måneders-, års- og livstidsprevalens registreres.

I oversiktsartikkelen fra Luppa og medarbeidere rapporteres punktprevalens av depresjon (Major depression - MDD) hos eldre over 75 år basert på 10 epidemiologiske studier publisert etter 1999 til gjennomsnittlig 7,2\% (4). Prevalensen varierer i de forskjellige studiene fra $4,6 \% \mathrm{i}$ en studie fra USA til $9,3 \%$ i en studie fra Storbritannia. I de fleste studiene med strukturerte diagnostiske intervju og kriteriebaserte diagnoser rapporteres det ikke økning av MDD blant eldre, de fleste studiene finner en uendret eller en nedgang $\mathrm{i}$ forekomsten. I studier med kategoriske diagnoser rapporteres kjønnsforskjeller med høyere forekomst hos kvinner. Generelt er kjønnsforskjellene større $\mathrm{i}$ disse studiene enn i studier med symptomskalaer med en kjønnsratio på ca 2,0.

\section{PreVAlens AV DEPRESJON I LONGITUDI- NELLE STUDIER}

Mens antallet tverrsnittsstudier av depresjon blant eldre i den generelle befolkning er stort, er det få longitudinelle studier med gjentatte målinger. Det er forskjeller på målemetode og studiedesign i disse studiene.

To klassiske nordiske epidemiologiske studier har gitt holdepunkter for økning av forekomst av depresjon. På Island fulgte Helgason og medarbeidere alle islendinger født i 1895-97 $(n=5395)$ fra 1910 til 1983 og fant en økning av forekomst av depresjon med økende alder (18). I Lundby-studien fra Sør-Sverige ble 2500 voksne fulgt fra 1940-årene med gjentatte målinger etter 10, 25 og 50 år og fant en betydelig økning av forekomst av depresjon i befolkningen (19).

I HUNT har vi i en nylig publisert studie målt utviklingen av prevalens i den eldre befolkning fra HUNT-2 (1995-97) til HUNT-3 (2006-08) (3). Vel 16500 eldre som deltok i begge HUNT-undersøkelsene med valide HADS-D skåre ble inkludert i studien og delt opp i 5 års kohorter. Vi fant en signifikant økning i prevalens av HADS-basert depresjon i de tre eldste kohorter (76 år + ved HUNT-3). I den eldste alderskohorten (86-90 år ved HUNT-3) økte prevalensen fra $11,3 \%$ ved HUNT-2 til $20,9 \%$ ved HUNT-3. Omtrent 5\% i alle alderskohorter rapporterte depresjon ved begge måletidspunkter (kronisk eller tilbakevendende depresjon), mens det var en betydelig andel nye depresjonskasus i de tre eldste alderskohortene.

Gøteborgstudien fulgte en kohort over 15 år og fant en økning av insidens og prevalens av depresjon basert på DSM-III kriteriene, samt en høyere insidens hos kvinner enn hos menn. Prevalensen av depresjon økte fra 5,6\% ved 70 år til 13,0\% ved 85 år (20).

\section{Prevalens AV DePResJon Ved deMenS}

Kognitiv svikt og demens er en hyppig forekommende lidelse blant eldre, og øker med alderen. Depresjon kan forekomme både som egen komorbid lidelse ved demens, og som ledsagende symptom til demenssykdommen (Behavioural and psychological symptoms of dementia (BPSD)) (21). Symptomene på depresjon kan forekomme både $\mathrm{i}$ tidlig fase og i senere fase av demenssykdommen, og symptombildet er ofte annerledes enn hos kognitivt friske. Depresjon og demens har noen felles symptomer, som redusert sosial aktivitet og tap av interesse, mens andre depressive symptomer er karakteristisk for depresjon hos pasienter med Alzheimers sykdom enn for depresjon hos kognitivt friske (22). De diagnostiske kriteriene i depressiv episode i diagnosesystemet (ICD 10 og DSM IV) har derfor begrensninger $\mathrm{i}$ forhold til å diagnostisere depresjon ved demens. I tillegg viser studier av forekomst av depresjon ved demens forskjellig forekomst i de forskjellige undergrupper av demens og forskjellige prevalenser blant yngre pasienter med demens sammenlignet med eldre.

Studier av depresjon ved demens varierer både når det gjelder utvalg (generell befolkning, kliniske populasjoner (i sykehjem, hjemmeboende) og målemetoder.

Generelt viser studier en økt forekomst av depresjon blant personer med demens sammenlignet med personer uten demens. Dette gjelder både studier hvor man anvender symptomskalaer og intervju og diagnostiske kriterier for å måle depresjon.

I en stor populasjonsbasert studie med over 5000 personer med demens fra USA ble depressive symp- 
tomer i verktøyet Neuropsychiatry inventory (NPI) brukt som symptommål. Studien rapporterte en prevalens på $24 \%$ av depresjon blant personer med demens (23). Med samme måleinstument fant Selbæk i en norsk sykehjemsstudie en prevalens av depresjon blant personer med demens på $41 \%$ (24).

En svensk populasjonsbasert studie brukte diagnostiske kriterier og intervju som mål på depresjon. De målte alvorlig depresjon etter DSM-IV kriterier. Denne studien rapporterer om en tre ganger så høy forekomst av alvorlig depresjon blant personer med demens sammenlignet med personer uten demens $(11,8 \%$ versus 3,9\%) (25). En kriteriebasert amerikansk studie av polikliniske pasienter med demens ved Alzheimer sykdom fant en prevalens av depresjon på ca. $25 \%$ (26).

Studier gir holdepunkter for at prevalens av depresjon er høyere hos yngre pasienter med demens sammenlignet med eldre. I en norsk studie fant Rosness og medarbeidere en prevalens på hele $66 \%$ i en populasjon av personer med demens under 65 år (27).

Studier tyder på at det er forskjellig prevalens av depresjon ved ulike demenssykdommer. Ballard og medarbeidere rapporterte om dobbelt så høy forekomst av depresjon blant pasienter med vaskulær demens sammenlignet med pasienter med demens ved Alzheimer sykdom (19\% versus 8\%) (28). Forekomst av depresjon hos pasienter med demens med Lewy-legemer er høy. I en studie fant Borrini og medarbeidere en forekomst på $60 \%$ (29).

I forbindelse med HUNT-undersøkelsen har vi i Nord-Trøndelag etablert et demensregister av personer som har utviklet demens i tiden etter HUNT-2 undersøkelsen. Registeret inneholder nå omkring 1000 personer som har en sikker demensdiagnose, og vi planlegger nå studier for å undersøke sammenhengen mellom depresjon og demens/etiologiske demensdiagnoser. I første omgang vil vi studere om rapportert depresjon ved HUNT-undersøkelsen eksponerer for senere utvikling av demens.

\section{DISKUSJON}

Prevalens av depresjon blant eldre i den generelle befolkning varierer fra studie til studie. Studier som bruker symptomskalaer rapporterer høyere prevalens enn studier som bruker strukturerte intervju og kategoriske diagnoser etter ICD- eller DSM diagnosesystemet. Flere forhold kan være årsak til de varierende resultatene, og vi vil i det følgende diskutere noen av de vi anser som viktigst.

\section{Forskjeller i utvalg}

Mange studier av den generelle befolkning inkluderer ikke personer som er innlagt institusjon, verken sykehus eller sykehjem/pleieinstitusjon. Andelen innlagt $\mathrm{i}$ institusjoner øker med alderen. Studier viser at depresjon og depresjonssymptomer forekommer hyppigere blant eldre innlagt institusjon (30). Studier som ekskluderer eldre i institusjon vil derfor måle for lav preva- lens av depresjon blant eldre. I HUNT-studien ble alle voksne innbyggere invitert, også de innlagt institusjon. Vi mangler informasjon om hvor stor andel av de som var innlagt institusjon som deltok. Vi antar at andelen var lavere enn i de eldre utenfor institusjon og at dette kan bidra til at våre prevalenstall er for lave.

Epidemiologiske studier av depresjon blant eldre bør inkludere eldre i institusjon om resultatene skal være representative for hele den eldre generelle befolkning.

\section{Forskjeller i deltagerandel}

Deltagelse og oppmøteprosent varierer fra de forskjellige studiene. I både symptomskalaundersøkelser og i studier med strukturerte intervju er det noen som motsetter seg å delta, og noen som er forhindret fra å delta. Blant eldre er somatisk sykdom og demens ofte årsaker til manglende deltagelse. I de fleste studiene av eldre er det fra 20\% til 50\% som ikke deltar. Fra denne andelen mangler studiene data på depresjon. I en generell helseundersøkelse fra Nord-Norge fant Hansen og medarbeidere ved kopling til helseregisterdata at de som ikke møtte hadde en prevalens av mentale lidelser to og en halv gang høyere enn de som møtte (31). Dersom dette også gjelder for depresjon og "missing" andelen er forskjellig i forskjellige studier vil dette kunne føre til forskjeller i prevalens av depresjon i studiene.

\section{Forskjellige måleinstrumenter}

Forskjeller på strukturerte intervju og symptomskala: Mens de strukturerte intervjuene har systematiske spørsmål om alle de symptomer som inngår i DSMeller ICD-definert diagnose, har spørreskjema spørsmål om et utvalg sentrale symptomer. Intervjuene gir data på varighet og tidspunkt for de depressive symptomene, mens spørreskjema gir data på symptomer på tiden for undersøkelsen og $\mathrm{i}$ et definert tidsrom, ofte 1 uke, forut for undersøkelsen. I intervju spørres det om funksjonssvikt, som er essensiell for en kriteriebasert diagnose, mens dette ikke fremgår av symptomskalaer. Mens symptomskalaer måler et dimensjonelt nivå på et utvalg depressive symptomer, måler de kriteriebaserte intervjuene etter strenge kriterier om diagnosesymptomer er til stede eller ikke, om de varer lenge nok og om de fører til funksjonsreduksjon.

Forskjeller mellom symptomskalaer: De forskjellige symptomskalaer som brukes i epidemiologiske undersøkelser måler forskjellige aspekter ved depresjon. Mens GDS er spesielt tilpasset depresjonssymptomer hos eldre er CES-D og HADS beregnet på hele den generelle voksne befolkning. Mens GDS og CES-D dekker et vidt spekter av depressive symptomer, måler flere av spørsmålene i HADS anhedoni (32). Ved HADS er somatiske symptomer ekskludert, og man unngår derfor at somatiske sykdommer hos eldre slår ut som depresjon på symptomskalaen.

Å finne gode måleinstrumenter for å påvise depresjon hos personer med demens er særlig utfordrende. De mest brukte symptomskalaer og diagnostiske inter- 
vjuer er ikke tilpasset personer med kognitiv svikt, og validiteten av resultatene kan påvirkes av manglende innsikt, forståelse og rapporteringsevne hos pasienten. Ofte er det nødvendig å innhente opplysninger fra nære pårørende/nære kontaktpersoner. Forskningen og fagfeltet trenger å utvikle mer valide måleinstrumenter for å måle depresjon hos personer med demens.

\section{STUDIER SOM KAN FORKLARE ØKNINGEN AV DEPRESJON BLANT ELDRE}

I internasjonale epidemiologiske forskningsmiljøer har det $\mathrm{i}$ de siste to tiår vært forsket på om det er det å bli eldre i seg selv som fører til økt forekomst av depresjon, eller om andre faktorer kan forklare økningen $(33,34)$. I store epidemiologiske undersøkelser har det vært gjennomført analyser som kontrollere for andre faktorer som kan ha sammenheng med depresjon hos eldre. Flere studier konkluderer med at den økte forekomst av depresjon har sammenheng med økt forekomst av kroniske somatiske sykdommer og funksjonssvikt $(5,7,14,16,33)$. Dette stemmer godt overens med de multivariate analysene vi har gjort ved HUNTstudien, der vi fant at somatisk sykdom med selvrapportert funksjonssvikt og redusert syn og hørsel kunne forklare noe av økningen av depresjon med alderen hos de over 60 år (2). Disse studiene tyder på at det ikke er depresjon som egen sykdom som øker med alderen, men depresjon komorbid til kroniske somatiske sykdommer.

Også demografiske faktorer (utdanning, ekteskapelig status) og sosiale faktorer (sosial isolasjon, manglende sosial støtte) har i studier av eldre vist seg å være faktorer som har sammenheng med depresjon og som kan forklare den økte prevalens av depresjon i høy alder $(2,5,33,34)$. Disse epidemiologiske studiene gir holdepunkter for at det ikke er det å bli eldre i seg selv som fører til økt forekomst av depresjon, men depresjon i sammenheng med andre faktorer.

\section{VIDERE FORSKNING}

Fagfeltet trenger mer forskning på depresjon hos eldre. Særlig er det behov for flere longitudinelle studier som kan beskrive utviklingen av depresjon i den eldre befolkningen over tid. I tillegg er det innen epidemiologisk forskning behov for forskning på risikofaktorer og beskyttende faktorer spesielt rettet mot depresjon blant eldre. Dette innebærer studier der både potensielle risikofaktorer/beskyttende faktorer og depresjon måles med valide, gode måleinstrumenter. Forskningsbasert kunnskap om påvirkbare risikofaktorer og beskyttende faktorer vil kunne gi grunnlag for målrettede forebyggende tiltak.

\section{REFERENCES}

1. Stordal E, Krüger MB, Dahl NH, et al. Depression in relation to age and gender in the general population: The Nord-Trøndelag Health Study (HUNT). Acta Psychiatr Scand 2001; 104: 210-16.

2. Stordal E, Mykletun A, Dahl AA. The association between age and depression in the general population: a multivatiate examination. Acta Psychiatr Scand 2003; 107: 132-41.

3. Solhaug HI, Romuld EB, Romild U, Stordal E. Increased prevalence of depression in cohorts of the elderly: an 11-year follow-up in the general population - the HUNT study. Int Psychogeriatr 2012; 24: 151-8.

4. Luppa M, Sikorski C, Luck T, et al. Age- and gender-spesific prevalence of depression in latest-life Systematic review and meta-analysis. J Affect Disord 2012; 136: 212-21.

5. Luppa M, Sikorski C, Luck T, et al. Prevalence and risk factors of depressive symptomes in latest life results of the Leipzig Longitudinal Study of the Aged (LEILE 75+). Int J Geriatr Psychiatry 2012; 27 (3): 286-95.

6. Stordal E, Bjelland I, Mykletun A, Dahl AA. Anxiety and depression in individuals with somatic health problems. The Nord-Trøndelag Health Study (HUNT). Scand J Prim Health Care 2003; 21: 136-41.

7. Scott KM, Von Korff M, Alonso J, et al. Age pattern in the prevalence of DSM-IV depressive/anxiety disorders with and without physical co-morbidity. Psychol Med 2008; 38: 1659-69.

8. Luppa M, Heinrich S, Angermeyer MC, et al. Cost-of-illness studies of depression: a systematic review. $J$ Affect Disord 2007; 98: 29-43.

9. Radloff LS. The CES-D Scale: a self-report depressive scale for research in the general population. Appl Psychol Measur 1977; 1: 385-401.

10. Zigmond AS, Snaith RP. The Hospital anxiety and depression scale. Acta Psychiatr Scand 1983; 67: $361-70$.

11. Brink TL, Yesavage JA, Lum O, et al. Screening tests for geriatric depression. Clinical Gerontologist 1982; 1: 37-43.

12. Bjelland I, Dahl AA, Tangen Haug T, et al. The validity of the Hospital Anxiety and Depression Scale. An updated literature review. J Psychosom Res 2002; 52: 69-77.

13. Mykletun A, Stordal E, Dahl AA. The Hospital Anxiety and Depression Scale (HADS): Factor structure, item analyses, and internal consistency in a large population. Br J Psychiatr 2001; 179: 540-4.

14. Beekman ATF, Penninx BWJH, Deeg DHJ, et al. Depression and physical health in later life: Results from the Longitudinal Aging Study Amsterdam (LASA). J Affect Disord 1997; 46: 219-31. 
15. Cornoni-Huntley J, Brock D, Ostfeld A, et al. Established Populations for Epidemiologic Studies of the Elderly: Resource Data Book. Bethesda, MD: National Institute on Aging, 1986.

16. Blazer D, Burchett B, Service C, et al. The association of age and depression among the elderly: an epidemiologic exploration. J Gerontol 1991; 46: M210-M215.

17. Robins LN, Wing J, Wittchen HU, et al. The Composite International Diagnostic Interview. Arch Gen Psychiatry 1988; 45: 1069-77.

18. Helgason T. Epidemiology of mental disorders in Iceland. Acta Psychiatr Scand 1964: Suppl 173.

19. Hagnell O, Lanke J, Rorsman B, et al. Are we entering an age of melancholy? Depressive illness in a prospective epidemiological study over 25 years: the Lundby study, Sweden. Psychol Med 1982; 12: 279-89.

20. Pàlsson SP, Östling S and Skoog I. The incidence of first-onset depression in a population followed from the age of 70 to 85 . Psychol Med 2001; 31: 1159-68.

21. Finkel S. Introduction to behavioural and psychological symptoms of dementia (BPSD). Int J Geriatr Psychiatry 2000; 15 Suppl 1: 2-4.

22. Olin JT, Katz IR, Meyers BS, et al. Provisional diagnostic criteria for depression of Alzheimer disease: rationale and background. Am J Geriatr Psychiatry 2002; 10: 129-41.

23. Lyketsos CG, Steinberg M, Tschanz JA, et al. Mental and behavioural disturbens in dementia: findings from the Cache County Study on memory and aging. Am J Psychiatry 2000; 157: 708-14.

24. Selbæk G, Kirkevold O, Engedal K. The prevalence of psychiatric symptoms and behavioural disturbances and the use of psychotropic drugs in Norwgian nursing homes. Int J Geriatr Psychiatry 2007; 22: 843-49.

25. Forsell Y, Winblad B. Major depression in a population of demented and nondemented older people: prevalence and correlates. J Am Geriatr Sos 1998; 46: 27-30.

26. Lyketsos CG, Steele C, Baker L, et al. Major and minor depression in Alzheimer's disease: prevalence and impact. J Neuropsychiatry Clin Neurosci 1997; 9: 556-61.

27. Rosness TA, Barca M, Engedal K. Occurrence of depression and its correlates in early onset dementia patients. Int J Geriatr Psychiatry 2010; 29: 438-47.

28. Ballard C, Neill D, O'Brien J, et al. Anxiety, depression and psychosis in vascular dementia: prevalence and associations. J Affect Disord 2000; 59: 97-106.

29. Borroni B, Agosti C, Padovani A. Behavioual and psychological symptoms in dementia with Lewy-bodies (DLB): frequency and relation with disease severity and motor impairment. Arch Gerontol Geriatr 2008; 46: 100-6.

30. Barca ML, Engedal A, Laks J, Selbeak G. A 12 month follow-up study of depression among nursing-home patients in Norway. J.Affect Disorders 2010; 120: 141-8.

31. Hansen V, Jacobsen BK, Arnesen E. Prevalence of serious psychiatric morbidity in attenders and nonattenders to a health survey of a general population. Am J Psychiatry 2001; 154: 891-4.

32. Snaith RP. Anhedonia: a neglected symptom of psychopathology. Psychol Med 1993; 23: 957-66.

33. Roberts RE, Kaplan GA, Shema SJ, Strawbridge WJ. Does growing old increase the risk for depression? Am J Psychiatry 1997; 154: 1384-90.

34. Jorm AF. Does old age reduce the risk of anxiety and depression? A review of epidemiological studies across the adult life span. Psychol Med 2000; 30: 11-22. 